\title{
Efficient asymmetric Baeyer-Villiger oxidation of prochiral cyclobutanones using new polymer-supported and unsupported chiral co(salen) complexes
}

\author{
REZA SANDAROOS ${ }^{\mathrm{a}, *}$, MOHAMMAD TAGHI GOLDANI $^{\mathrm{b}, *}$, SAMAN DAMAVANDI $^{\mathrm{c}}$ and \\ ALI MOHAMMADI ${ }^{d}$ \\ ${ }^{a}$ Department of Chemistry, Faculty of Science, University of Birjand, Birjand, Iran \\ ${ }^{b}$ Department of Chemistry, Islamic Azad University, Birjand Branch, Birjand, Iran \\ ${ }^{c}$ Department of Chemistry, Faculty of Science, Ferdowsi University of Mashhad, Mashhad, Iran \\ ${ }^{\mathrm{d}}$ Department of Chemistry, Sarvestan Branch, Islamic Azad University, Sarvestan, Iran \\ e-mail: R_Sandaroos@yahoo.com; MT.Goldani@yahoo.com
}

MS received 31 January 2012; accepted 8 March 2012

\begin{abstract}
Two heterogeneous catalysts $\mathbf{4}$ and $\mathbf{5}$ and three homogenous complexes 1-3 were prepared and used for enantioselective Baeyer-Villiger (B-V) oxidation of prochiral cyclobutanones. Among the prepared catalysts, the supported ones showed better enantioselectivity, good thermal stability and negligible loss of activity over consecutive recycling offset by lower chemical yield.
\end{abstract}

Keywords. Polymer-supported; enantioselective; Baeyer-Villiger oxidation; cyclobutanones; Co(Salen) Complexes.

\section{Introduction}

B-V oxidation is a very old and valuable chemical transformation that was first discovered in $1899^{1}$ and subsequently converted into a catalytic process in $1993 .{ }^{2}$ Despite its long history, its enantioselective version using transition metal catalysts is relatively recent. $^{3-12}$

$\mathrm{B}-\mathrm{V}$ oxidation is a two-step reaction: (i) nucleophilic addition of an oxidant giving the Criegee adduct and (ii) rearrangement of the adduct to ester (or lactone). If the starting carbonyl compound is a pro-chiral cyclic one, the products are a pair of enantiomeric lactones (figure 1). The stereochemistry of the $\mathrm{B}-\mathrm{V}$ reaction is dictated by two factors: face selectivity in oxidant addition and enantiotopos selectivity in migration. However, as Criegee adduct formation is a reversible step and its migration to lactone is an irreversible and ratedetermining one, topos-selection in the migration step is considered to strongly influence the stereochemistry of $\mathrm{B}-\mathrm{V}$ reaction. Interaction of the $\sigma$-orbital of the migrating $\mathrm{C}-\mathrm{C}$ bond and the $\sigma^{*}$-orbital of the $\mathrm{O}-\mathrm{O}$ bond is crucial for the migration. ${ }^{13}$ Therefore, it was expected that high enantioselectivity would be achieved if the

*For correspondence $\sigma$-bond interacts with the $\sigma^{*}$-bond topos-selectively. It was also considered that the topos-selective interaction would be realized if the Criegee adduct makes a chelate (Criegee adduct B), and the chelate conformation is regulated appropriately. Furthermore, a metallosalen complex with cis-structure was considered to be a suitable catalyst for this purpose, because it provides two neighbouring coordinating sites for chelate formation and its metal center is chiral. ${ }^{4}$

As discussed above, each factor shifting the equilibrium between intermediates $\mathrm{A}$ and $\mathrm{B}$ toward intermediate $\mathrm{B}$, must increase enatioselectivitiy of the reaction. Accordingly, unfavourable steric hindrance next to the center of reaction introduced by ligand, substrate or oxidant proceeds reaction through the less sterically congested transition state A.

$[\mathrm{Co}($ salen $)]$ s show high asymmetric induction ${ }^{14,15}$ and high Lewis acidity. ${ }^{15}$ In addition, it has been reported that iron, manganese, titanium and some of the cobalt complexes of Schiff base took $c i s-\beta$ structure. ${ }^{4,16,17}$ On the other hand, it has been reported that electronwithdrawing groups on the salen ligand of the $\mathrm{Cu}(\mathrm{III})$ complexes increase enatioselectivitiy of such a reaction. ${ }^{5}$

Keeping these considerations in our mind and in order to investigate electronic and steric effects of ligands on the enantioselectivity and the chemical yield of B-V oxidations, we have synthesized three chairal complexes 1-3, bearing three different salen ligands. 


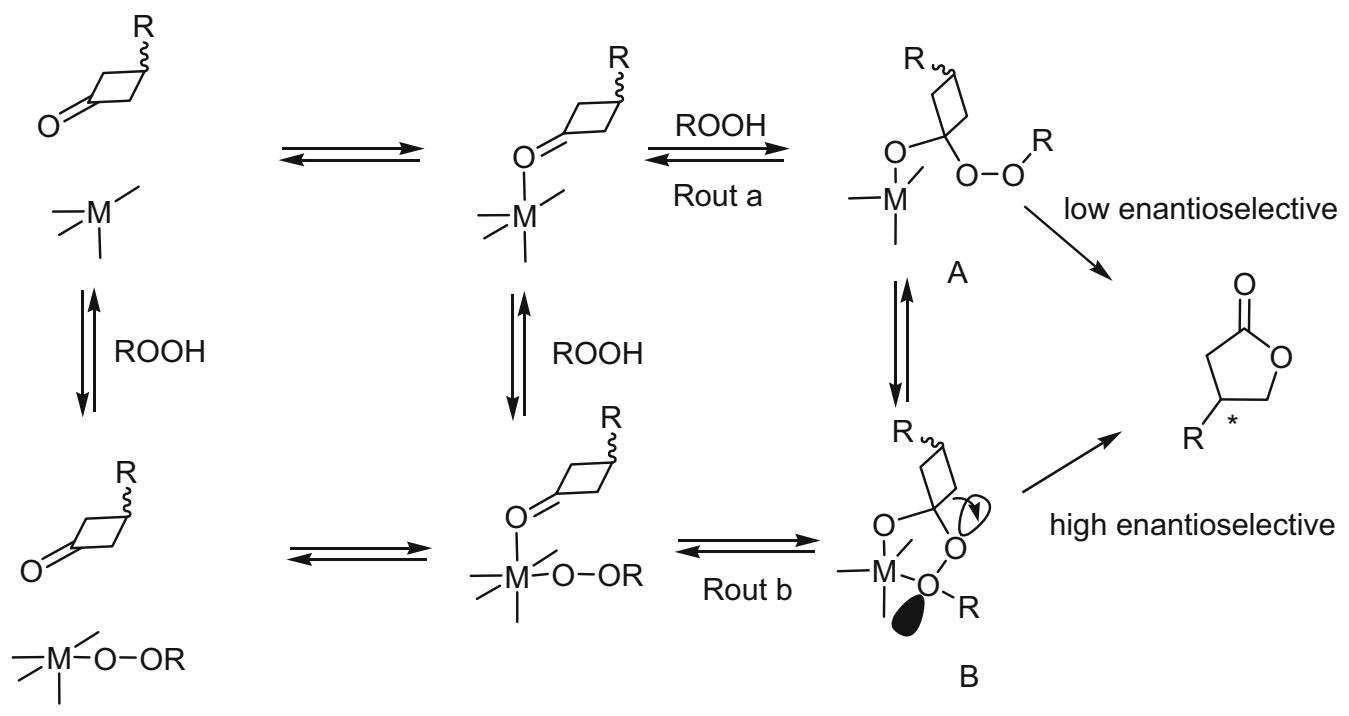

Figure 1. Schematic representation of M-adduct complexes.

Despite high efficiency of catalysts $\mathbf{1}$ and $\mathbf{2}$ for asymmetric $\mathrm{B}-\mathrm{V}$ reactions, separation of these from the reaction mixture was a serious problem. Additionally, in order to investigate probable supporting effects, we prepared polymer-supported catalysts $\mathbf{4}$ and $\mathbf{5}$, which were nearly heterogeneous types of catalysts $\mathbf{1}$ and $\mathbf{2}$.

\section{Experimental}

\subsection{General}

All solvents and commercially available starting materials were supplied by Merk Chemical Co. (Darmstadt, Germany) and Fluka Co. and were used as received. The 3-substituted cyclobutanones were prepared according to the literatures. ${ }^{18,19}{ }^{1} \mathrm{HNMR}$ and IR spectrums were recorded on a Bruker BRX-100 AVANCE and Shimadzu-IR 470 spectrometer, respectively. Elemental analysis for $\mathrm{CHN}$ was carried out by the $\mathrm{CHNO}$ type from the Helaus Co.

\subsection{General procedures}

Complex $\mathbf{2}$ was synthesized according to Katsuki's procedure. $^{7 \mathrm{c}}[\mathrm{Co}($ salen $)]$ complexes $\mathbf{1}$ and $\mathbf{3}$ were also synthesized similarly (figure 2).

2.2a [Co(salen)] complex 1: Brown solid. IR (KBr): 3090, 3005, 2912, 2910, 1612, 1554, 1500, 1486, 1436, $1387,1315,1210,1182,1124,1076,1036,989,927$, 871, 822, 802, 742, 692, 572, 522, 492. Anal. calc. for $\mathrm{C}_{34} \mathrm{H}_{18} \mathrm{CoIN}_{6} \mathrm{O}_{10}$ : C, 47.68; H, 2.12; N, 9.81; found: C, 47.11; H, 2.01; N, 9.76.
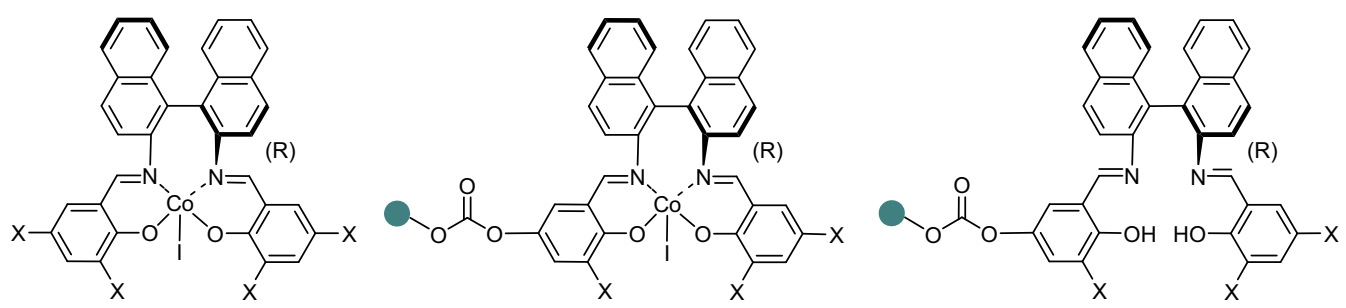

[Co(salen)] 1: $\mathrm{X}=\mathrm{NO}_{2}$ [Co(salen)] 2: X $=\mathrm{F}$
$[\mathrm{Co}($ salen)] $3: \mathrm{X}=\mathrm{t}-\mathrm{Bu}$
[Co(salen)]-PSI 4 and immobilized form of ligand $A: X=F$ [Co(salen)]-PSI 5 and immobilized form of ligand $\mathrm{B}: \mathrm{X}=\mathrm{NO}_{2}$

Figure 2. Structures of Co(III)(salen) complexes 1-5 and ligands $\mathbf{A}$ and $\mathbf{B}$. 
2.2b [Co(salen)] complex 3: Brown solid. IR ( $\mathrm{KBr})$ : 3059, 2957, 2916, 2870, 1593, 1470, 1419, 1250, 1200, 1173, 1115, 1076, 1028, 984, 922, 809, 798, 739, 681, 561, 509, 484. Anal. calc. for $\mathrm{C}_{50} \mathrm{H}_{54} \mathrm{CoIN}_{2} \mathrm{O}_{2}$ : C, 66.67; H, 6.04; N, 3.11; found: C, 66.59; H, 6.00; N, 3.02 .

Polymer-bound ligands $\mathbf{A}$ and $\mathbf{B}$ were prepared according to Jacobsen's procedure ${ }^{15 b}$ (figure 2). To a solution of 2-hydroxy-3,5-dinitrobenzaldehyde $(0.7 \mathrm{mmol})$ and 2,6-dihydroxy-3-nitrobenzaldehyde $(0.7 \mathrm{mmol})$ in EtOH was added (1R)-1,1'-binaphthalene-2,2'-diamine $(0.7 \mathrm{mmol})$ and the mixture was refluxed for $4 \mathrm{~h}$. After cooling to room temperature (rt), the resulting yellow foam was filtered off and dried in vacuo. Dissymmetric ligand $\mathbf{B}$ was separated from the mixture by column chromatography (eluent: diethyl ether/hexanes, 1:20). Dissymmetric ligand A was prepared similarly.

2.2c Dissymmetric ligand $B$ : Yellow solid. ${ }^{1} \mathrm{HNMR}$ $\left(\mathrm{CDCl}_{3}, 100 \mathrm{MHz}\right): \delta 7.1-7.9(\mathrm{~m}, 12 \mathrm{H}), 8.5(\mathrm{~s}, 1 \mathrm{H})$, $8.8(\mathrm{~s}, 1 \mathrm{H}), 9.3(\mathrm{~s}, 1 \mathrm{H}), 13.0(\mathrm{bs}, 1 \mathrm{H})$. Anal. calc. for $\mathrm{C}_{34} \mathrm{H}_{21} \mathrm{~N}_{5} \mathrm{O}_{9}: \mathrm{C}, 63.45 ; \mathrm{H}, 3.29$; N, 10.88; found: $\mathrm{C}$, $63.21 ; \mathrm{H}, 3.21 ; \mathrm{N}, 10.80$.

2.2d Dissymmetric ligand A: Yellow solid. ${ }^{1} \mathrm{HNMR}$ $\left(\mathrm{CDCl}_{3}, 100 \mathrm{MHz}\right): \delta 6.9-7.8(\mathrm{~m}, 16 \mathrm{H}), 8.4(\mathrm{~s}, 1 \mathrm{H}), 13.2$ (bs, $1 \mathrm{H}$ ). Anal. calc. for $\mathrm{C}_{34} \mathrm{H}_{21} \mathrm{~F}_{3} \mathrm{~N}_{2} \mathrm{O}_{3}: \mathrm{C}, 72.59 ; \mathrm{H}$, 3.76; N, 4.98; found: C, 72.36; H, 3.71; N, 4.91 .

For immobilization of ligads $\mathbf{A}$ and $\mathbf{B}$, hydroxymethyl polystyrene resin (Advanced Chemtech, 2\% cross-linked $90 \mu \mathrm{m}$ beads, $0.8 \mathrm{mmol} / \mathrm{g}$ ) were firstly activated by 4-nitrophenyl chloroformate according to the Jacobsen's work. ${ }^{15 \mathrm{~b}}$ An excess amount of 4nitrophenyl chloroformate reagent was used to obtain maximum conversion of $\mathrm{OH}$. IR spectra of products showed no absorption at $3460 \mathrm{~cm}^{-1}(\mathrm{OH})$. Moreover, the introduction of 4-nitrophenyl carbonate into polymer matrix resulted strong bands at $1770(\mathrm{C}=\mathrm{O})$ (for the both ligands), 1535,1345 and $870 \mathrm{~cm}^{-1}\left(\mathrm{NO}_{2}\right)$ (for ligand $\mathbf{A}$ ).

To a suspension of activated resin $(0.4 \mathrm{mmol})$ in anhydrous DMF (5.0 mL) was added ligand A $(0.59 \mathrm{mmol})$, DMAP $(0.4 \mathrm{mmol})$, and DIPEA $(0.8 \mathrm{mmol})$. The resulting orange suspension was shaken at room temperature for $1.5 \mathrm{~h}$, then filtered and rinsed sequentially with $\mathrm{DMF}, \mathrm{MeOH}$ and $\mathrm{CH}_{2} \mathrm{Cl}_{2}$ and dried in vacuo to yield orange beads as Polymer-bound ligand A. Polymer-bound ligand $\mathbf{B}$ were synthesized in the same manner. Strong bands observed at 1630 $1642 \mathrm{~cm}^{-1}(\mathrm{C}=\mathrm{N})$ (for the both ligands) with disappearance of bands at 1530, 1350 and $860 \mathrm{~cm}^{-1}\left(\mathrm{NO}_{2}\right)$ (for the ligand $\mathbf{A}$ ) in the IR spectra indicated the high conversion of activated resin to the suitable polymer-bound ligands.

Cobalt insertion into the polystyrene-bound ligands was accomplished by adding solution of $\mathrm{Co}(\mathrm{OAc})_{2}$ $(0.4 \mathrm{mmol})$, which was obtained by heating $\mathrm{Co}(\mathrm{OAc})_{2}$. $4 \mathrm{H}_{2} \mathrm{O}$ at $70-80^{\circ} \mathrm{C}$ under vacuum until its colour turned from pink to purple, in $5 \mathrm{ml}$ of degassed $\mathrm{MeOH} /$ Toluen $1: 1$ to the polymer-bound ligand $(0.4 \mathrm{mmol})$ with gentle stirring. The mixture was heated at $60^{\circ} \mathrm{C}$ for $24 \mathrm{~h}$ and then evaporated and the residue suspended in $\mathrm{CH}_{2} \mathrm{Cl}_{2}$ $(15 \mathrm{ml})$. To this mixture, $\mathrm{I}_{2}(0.2 \mathrm{mmol})$ was added. After stirring for $4 \mathrm{~h}$, the mixtures was evaporated and the residue was rinsed with toluene and $\mathrm{CH}_{2} \mathrm{Cl}_{2}$ several times to obtain complexes $\mathbf{4}$ and $\mathbf{5}$.

Complexing of cobalt ions by polymer-bound ligand resulted in shifting of the imine absorption band location towards lower frequency (about $15 \mathrm{~cm}^{-1}$ ). Elemental analysis of complexes $\mathbf{4}$ and $\mathbf{5}$ indicated 1.81 and $1.86 \% \mathrm{Co}$, respectively, corresponding to a final loading of almost $0.30 \mathrm{mmol} / \mathrm{g}$ of Co. Procedure of B-V oxidation was followed from Katsuki's procedure. ${ }^{4}$

Table 1. Effects of oxidant, substituent and supporting on enantioselectivity and chemical yield of $\mathrm{B}-\mathrm{V}$ oxidation.

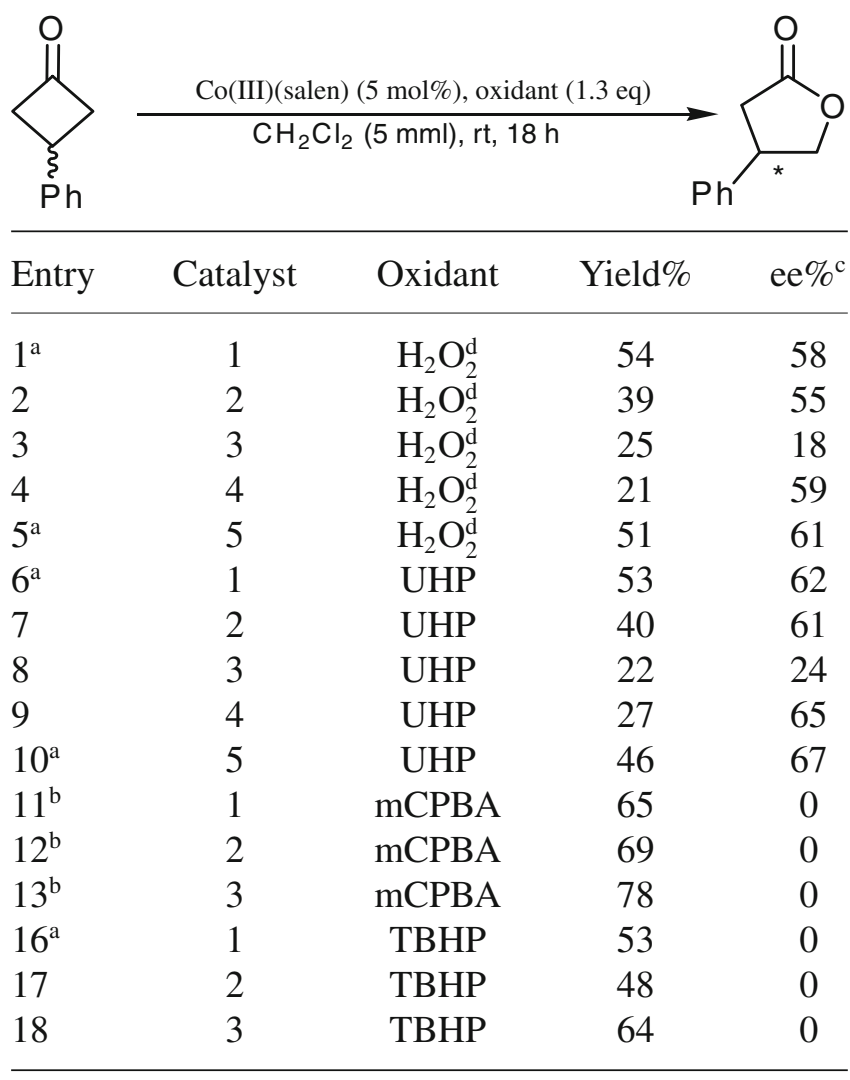

${ }^{a}$ Reaction was stirred for 30 minutes. ${ }^{b}$ Reaction was carried out at $-78^{\circ} \mathrm{C}$ in the presence of 1 equiv. of $N$ methylmorpholine $N$-oxide. ${ }^{\mathrm{c}}$ Determined by GC column LipodexB. ${ }^{\mathrm{d}}$ Aqueous hydrogen peroxide $(30 \%)$ 


\section{Results and discussions}

Complexes 1-5 were examined for asymmetric B-V oxidation of 3-phenylcyclobutanone by different oxidants (table 1). Just for comparison, we used catalyst $\mathbf{2}$ reported already by Katsuki et al. ${ }^{7 \mathrm{c}}$

The order of enentioselectivity and chemical yield of reactions using catalyst $\mathbf{1 - 3}$ was revealed as $\mathbf{1}>\mathbf{2}>\mathbf{3}$ (table 1, entries 1-3). Among the examined reactions, the one was performed with a combination of $\mathrm{H}_{2} \mathrm{O}_{2}$ and catalyst $\mathbf{1}$, bearing a ligand with four strong withdrawing substituents of $\mathrm{NO}_{2}$, showed the moderate chemical yield of $54 \%$ and good enentioselectivity of $58 \%$ at a short time of 30 minutes (table 1, entry 1). Catalyst 2 catalysed such a reaction with comparable enentioselectivity, but with lower yield and longer time of reaction (table 1, entry 2). On the other hand, four steric substituents of $t$-butyl, on the catalyst $\mathbf{3}$ were considered to decrease enentioselectivity to the extent of $18 \%$ (table 1 , entry 3). The unfavourable steric effect introduced by four $t$-Butyl groups lead reaction to proceed mainly through the non-chelated Criegee adduct A, resulting in low enentioselectivity.
Reactions performed by $\mathrm{H}_{2} \mathrm{O}_{2}$ in the presence of supported catalysts $\mathbf{4}$ and $\mathbf{5}$ showed slightly better enentioselectivities (59\% and $61 \%$, respectively) offset by lower chemical yields (table 1, entries 1, 2, 4, 5).

Furthermore, the use of UHP (urea. $\mathrm{H}_{2} \mathrm{O}_{2}$ adduct) instead of aqueous $\mathrm{H}_{2} \mathrm{O}_{2}$, for all the reactions, slightly improved enentioselectivities (table 1, entries 6-10). Additionally, the reactions performed with a combination of catalyst 1-3 and mCPBA (meta-chloroperbenzoic acid) or TBHP ( $t$-butyl hydroperoxide) as oxidants showed no enentioselectivities (table 1, entries 1118). This probably suggested that the oxidants such as TBHP and $m$-CPBA attacked the carbonyl group in an intermolecular fashion giving non-chelated Criegee adduct $\mathrm{A}$, while hydrogen peroxide was coordinated to the metal ion and attacked the carbonyl group to give chelated Criegee adduct B (figure 1).

The effects of solvent and temperature on enantioselectivities and chemical yields of the above reactions by UHP in the presence of catalysts 1-5 were also examined (table 2). Al reactions performed in polar solvents such as AcOEt, $\mathrm{CH}_{3} \mathrm{CN}$, THF and alcohols showed slightly better enantioselectivities and chemical yields

Table 2. Effects of solvent and temperature on enantioselectivity and chemical yield of B-V oxidation.

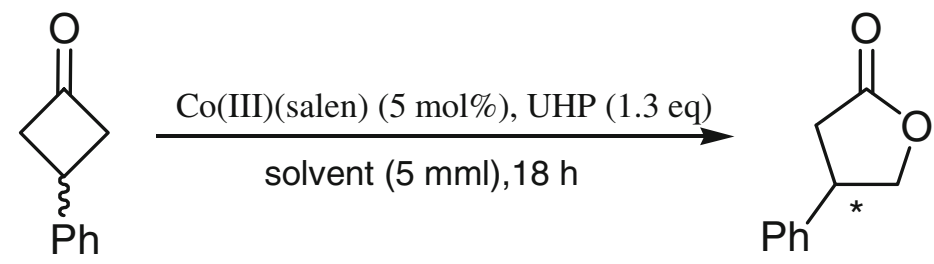

\begin{tabular}{|c|c|c|c|c|c|c|c|c|c|c|c|c|}
\hline \multirow[t]{3}{*}{ Entry } & \multirow[t]{3}{*}{ Solvent } & \multirow[t]{3}{*}{ Temperature } & \multicolumn{5}{|c|}{ Yield\% } & \multicolumn{5}{|c|}{$\mathrm{ee} \%^{\mathrm{a}}$} \\
\hline & & & \multicolumn{5}{|c|}{ Catalyst NO. } & \multicolumn{5}{|c|}{ Catalyst NO. } \\
\hline & & & $1^{\mathrm{b}}$ & 2 & 3 & 4 & $5^{b}$ & $1^{\mathrm{b}}$ & 2 & 3 & 4 & $5^{\mathrm{b}}$ \\
\hline 1 & EtOH & $-10^{\circ} \mathrm{C}$ & 75 & 56 & 36 & 53 & 67 & 80 & 75 & 35 & 77 & 83 \\
\hline 2 & $\mathrm{EtOH}$ & $0^{\circ} \mathrm{C}$ & 72 & 54 & 33 & 46 & 64 & 77 & 71 & 32 & 75 & 81 \\
\hline $3^{c}$ & $\mathrm{EtOH}$ & $0^{\circ} \mathrm{C}$ & 73 & 51 & 35 & 48 & 63 & 76 & 72 & 34 & 76 & 80 \\
\hline 4 & $\mathrm{EtOH}$ & RT & 62 & 48 & 31 & 43 & 53 & 73 & 70 & 30 & 74 & 79 \\
\hline 5 & Hexan & RT & 55 & 39 & 19 & 25 & 45 & 61 & 59 & 19 & 65 & 68 \\
\hline 6 & Toluene & RT & 39 & 21 & 15 & 19 & 40 & 68 & 65 & 23 & 67 & 70 \\
\hline 7 & Benzene & RT & 41 & 19 & 16 & 17 & 37 & 60 & 58 & 21 & 64 & 67 \\
\hline 8 & $\mathrm{CH}_{2} \mathrm{Cl}_{2}$ & $\mathrm{RT}$ & 53 & 40 & 22 & 27 & 46 & 62 & 61 & 24 & 65 & 67 \\
\hline 9 & $\mathrm{AcOEt}$ & $\mathrm{RT}$ & 64 & 47 & 27 & 34 & 51 & 71 & 68 & 28 & 72 & 75 \\
\hline 10 & $\mathrm{CH}_{3} \mathrm{CN}$ & RT & 59 & 44 & 26 & 32 & 48 & 70 & 69 & 27 & 71 & 76 \\
\hline 11 & THF & RT & 59 & 48 & 25 & 36 & 51 & 71 & 67 & 28 & 70 & 73 \\
\hline 12 & $\mathrm{EtOH}$ & $30^{\circ} \mathrm{C}$ & 54 & 39 & 27 & 41 & 52 & 64 & 60 & 21 & 73 & 79 \\
\hline 13 & $\mathrm{EtOH}$ & $40^{\circ} \mathrm{C}$ & 46 & 28 & 18 & 41 & 53 & 51 & 46 & 11 & 71 & 77 \\
\hline
\end{tabular}

${ }^{a}$ Determined by GC column Lipodex B, absolute configuration not assigned. ${ }^{b}$ Reaction was stirred for 30 minutes. ${ }^{\mathrm{c}}$ Aqueous hydrogen peroxide (30\%) was used as terminal oxidant 
Table 3. Asymmetric B-V oxidation of 3arylphenylcyclobutanone in the presence of fresh and recycled [Co(salen)]-PSI 5.

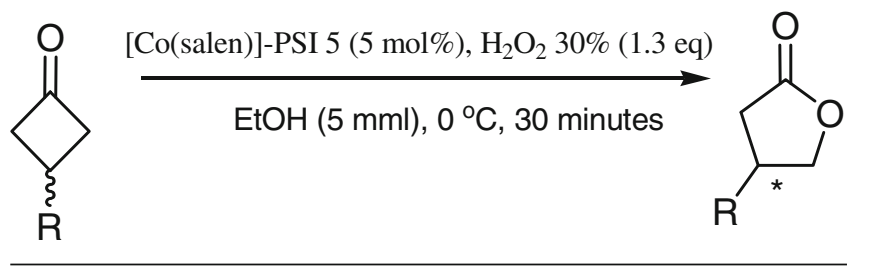

\begin{tabular}{lccc}
\hline Entry & $\mathrm{R}$ & Yield $\%$ & ee\% \\
\hline 1 & $4-\mathrm{MeOC}_{6} \mathrm{H}_{4}$ & 66 & 79 \\
$2^{\mathrm{b}}$ & $4-\mathrm{MeOC}_{6} \mathrm{H}_{4}$ & 65 & 79 \\
$3^{\mathrm{c}}$ & $4-\mathrm{MeOC}_{6} \mathrm{H}_{4}$ & 63 & 78 \\
$4^{\mathrm{d}}$ & $4-\mathrm{MeOC}_{6} \mathrm{H}_{4}$ & 64 & 80 \\
$5^{\mathrm{e}}$ & $4-\mathrm{MeOC}_{6} \mathrm{H}_{4}$ & 65 & 78 \\
6 & $4-\mathrm{MeC}_{6} \mathrm{H}_{4}$ & 59 & 77 \\
7 & $\mathrm{Ph}_{8}$ & 50 & 75 \\
8 & $4-\mathrm{BrC}_{6} \mathrm{H}_{4}$ & 47 & 66 \\
9 & $4-\mathrm{ClC}_{6} \mathrm{H}_{4}$ & 39 & 61 \\
10 & $4-\mathrm{FC}_{6} \mathrm{H}_{4}$ & 32 & 54 \\
\hline
\end{tabular}

${ }^{a}$ Determined by GC column Lipodex B. ${ }^{b-e}$ Reusability of the recovered catalyst in new runs

than those in non-polar solvents such as hexane, toluene and $\mathrm{CH}_{2} \mathrm{Cl}_{2}$ (table 2, entries 4-11).

Lowering the reaction temperature particularly to $-10^{\circ} \mathrm{C}$ improved enantioselectivities and chemical yields of all the reactions (table 2, entries 1 and 2). At $-10^{\circ} \mathrm{C}$, the reaction performed by UHB in the presence of catalyst 5 revealed good enantioselectivity of $83 \%$ (table 2, entry 1).

It is noteworthy that aqueous $\mathrm{H}_{2} \mathrm{O}_{2}(30 \%)$ can be used as terminal oxidant nearly as efficiently as UHP when ethanol was used as solvent (table 2, entries 2 and 3). On the other hand, raising temperature up to $40^{\circ} \mathrm{C}$ adversely affected the enantioselectivities and chemical yields obtained by homogeneous catalysts 1-3 while those were obtained by heterogeneous catalysts $\mathbf{4}$ and $\mathbf{5}$ nearly remained constant (table 2, entries 12,13 ).

Additionally, various 3-substituted cyclobutanones by UHP in the presence of [Co(salen)]-PSI 5 were oxidized (table 3). The enantioselectivities and chemical yields of reactions were influenced by the electronic properties of the substrates. Derivatives bearing more electrondonating groups of methoxy and methyl were converted into the corresponding lactones with higher enantioselectivities and chemical yields (table 3, entries 1, 6-10).

Finally, our study revealed that $[\mathrm{Co}($ salen)]-PSI 5 could be reused without significant loss of its enantioselectivity by at least 4 times (table 3 , entries $2-5$ ).

\section{Conclusion}

This study demonstrates the synthetic applicability of homogeneous [Co(salen)] and heterogeneous [Co(salen)]-PSI complexes in B-V oxidation of 3arylcyclobutanones. Our studies revealed that electron deficiency of catalyst increases enantioselectivity and chemical yield of $\mathrm{B}-\mathrm{V}$ reactions as long as these catalysts possess enough space for formation of the chelated Criegee adduct $\mathrm{B}$. The attachment of $[\mathrm{Co}($ salen) $]$ complexes on the functionalized polystyrene provides catalysts $\mathbf{4}$ and $\mathbf{5}$ which can be reused several times without significant loss of their activities. We have also demonstrated that supported catalysts $\mathbf{4}$ and $\mathbf{5}$ are featured by: (i) no significant loss of enantioselectivity in the catalytic systems with increasing of temperature up to $40^{\circ} \mathrm{C}$; (ii) higher enantioselectivity in comparison with their homogeneous analogues.

\section{References}

1. Baeyer V and Villiger B 1899 Dtsch. Chem. Ges. 32 3625

2. Del Todesco Frisone M, Pinna F and Strukul G 1993 Organometallics 12148

3. (a) Strukul G 1998 Angew. Chem. 110 1256; (b) ten Brink G J, Arends I W C E and Sheldon R A 2004 Chem. Rev. 104 4105; (c) Renz M and Meunier B 1999 Eur. J. Org. Chem. 737

4. Uchida T and Katsuki T 2001 Tetrahedron Lett. 426911

5. Bolm C, Schlingloff G and Weickhardt K 1994 Angew. Chem. 1061944

6. Bolm C, Khanh Luong T K and Schlingloff G 1997 Synlett. 1151

7. (a) Ito K, Ishii A, Kuroda T and Katsuki T 2003 Synlett. 0643; (b) Malkov A V, Friscourt F, Bell M, Swarbrick M E and Kochovsky P 2008 J. Org. Chem. 73 3996; (c) Uchida T and KatsukiHelvetica T 2002 Chemica. Acta. 853078

8. Paneghetti C, Gavagnin R, Pinna F and Strukul G 1999 Organometallics 185057

9. (a) Watanabe A, Uchida T, Irie R and Katsuki T 2004 Proc. Natl. Acad. Sci. 101 5737; (b) Bolm C and Beckmann O 2000 Chirality 12523

10. Matsumoto K, Watanabe A, Uchida T, Ogi K and Katsuki T 2004 Tetrahedron Lett. 452385

11. Bolm C, Beckmann O, Cosp A and Palazzi C 2001 Synlett. 1461

12. (a) Bolm C, Frison J C, Zhang Y and Wulff W D 2004 Synlett. 1619; (b) Frison J C, Palazzi C and Bolm C 2006 Tetrahedron 62 6700; (c) Bolm C, Beckmann O, Palazzi C, Adam W, Bheema Rao P and Saha-Mçller C R 2001 Tetrahedron: Asymmetry 12 2441; (d) Bolm C, Beckmann O and Palazzi C 2001 Can. J. Chem. 791593

13. Kelly D R 2000 Chem. Oggi./Chem. Today 1833 
14. (a) Fukuda $\mathrm{T}$ and Katsuki $\mathrm{T} 1995$ Synlett. 825; (b) Fukuda T and Katsuki T 1996 Tetrahedron Lett. 374389

15. (a) Tokunaga M, Larrow J F, Kakiuchi F and Jacobsen E N 1997 Science 277 936; (b) Ready J M and Jacobsen E N 1999 J. Am. Chem. Soc. 1216086

16. Saito B and Katsuki T 2001 Tetrahedron Lett. 423873
17. Cheng M C, Chang M C W, Peng S M, Cheung K K and Che C M 1997 J. Chem. Soc. Dalton Trans. 3479

18. Schmit C, Falmagne J B, Escudero J, Vanlierde H and Ghosez L 1990 Org. Synth. 69199

19. Kelly D R, Knowles C J, Mahdi J G, Wright M A, Taylor I N and et al 1995 J. Chem. Soc. Perkin Trans. 12057 